\title{
PRELIMINARY DESIGN OF A WIND DRIVEN VESSEL DEDICATED TO HYDROGEN PRODUCTION
}

\author{
Jean-Christophe Gilloteaux \\ LHEEA Lab, Ecole Centrale Nantes - CNRS \\ 1 rue de la Noë, Nantes, France \\ Jean-christophe.gilloteaux@ec-nantes.fr
}

\author{
Aurélien Babarit \\ LHEEA Lab, Ecole Centrale Nantes - CNRS \\ 1 rue de la Noë, Nantes, France \\ Aurelien.babarit@ec-nantes.fr
}

\begin{abstract}
An innovative concept of harnessing wind energy is presented. The concept consists of a wind driven ship equipped with a hydro-generator that converts the kinetic energy of the water flow into electricity. The electricity is then converted into hydrogen by electrolysis. In the present study the use of a Flettner rotor is considered to propel the ship. A mathematical model of the hydrogen producing ship is developed based on existing data for high performance ship hulls and aerodynamic coefficients of existing Flettner rotors. The design is optimized with respect to the axial induction velocity through the water turbine disk. Results indicate that a $22 \mathrm{~m}$ long vessel could produce $200 \mathrm{~kW}$ while a $80 \mathrm{~m}$ long vessel is able to generate 1 MW of mechanical power both for a true wind speed of $8 \mathrm{~m} / \mathrm{s}$.
\end{abstract}

\section{INTRODUCTION}

Currently, the worldwide renewable energy capacity is mainly composed of onshore wind energy and solar energy. In 2015, renewables contributed to $19 \%$ of the humans' global energy consumption [1]. To reach the target of limiting global warming to $2^{\circ} \mathrm{C}$ between now and 2100 , it is then necessary to continue the development of renewable energies. Most recently, offshore wind energy capacity grew significantly, especially in Northern Europe with bottom-fixed foundation and may significantly contribute to the worldwide electricity production in a near future. Along with the development of renewables, it is also necessary to find alternatives to fossil fuels. These alternatives could be biofuels, electric vehicles with storage system or electric vehicles using fuel cells and hydrogen. This is the scope of the present work with the presentation of preliminary results about the design and performance of an original concept for the conversion of offshore wind energy into hydrogen.

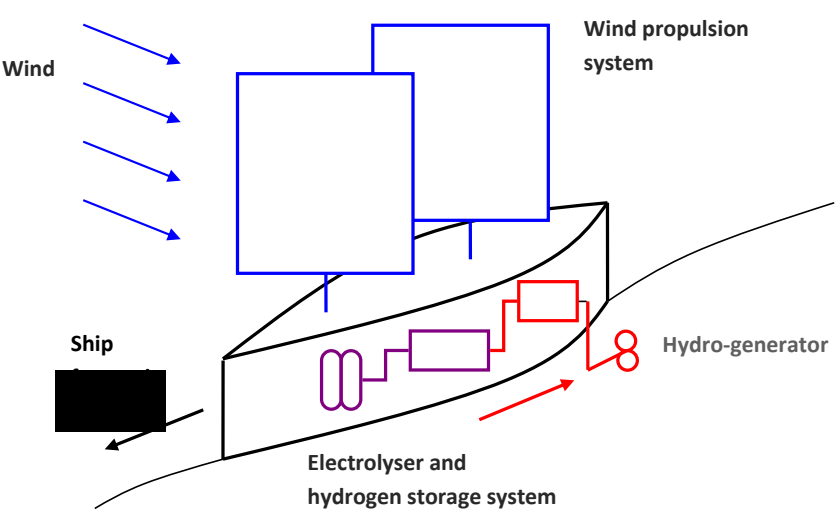

FIGURE 1: PRINCIPLE OF A WIND DRIVEN SHIP DEDICATED TO HYDROGEN PRODUCTION.

The working principle is relatively simple (cf. Figure 1): wind is used to propel a ship, a hydro-generator converts the ship's kinetic energy into electricity and the generated electricity is converted into hydrogen. The concept has several advantages in comparison to other wind energy conversion systems:

- Ship can sail to areas where wind resource is favorable, in other words it means that the concept might tend to a greater capacity factor;

- No need of mooring systems, or grid connection that could turn to considerable savings on CAPEX and considerable savings on financial costs;

- Ship can sail back to port for maintenance that might lead to a smaller OPEX.

The concept has however some drawbacks: 
- Part of the absorbed power is consumed to propel the ship;

- Part of the absorbed power is lost in the electrolysis process.

The main principle of the concept is not novel since the first patent about such a system was filled in 1982 by Salomon [2]. However, scientific investigations on the concept started only recently $[3,4]$. The main differences among those works are in the means used to convert wind energy into thrust force. Kim investigated the use of kites whereas Peltz investigated the use of air foils.

The present study corresponds to preliminary results on the design of the concept described above. Here the ship is assumed to be a catamaran and the propelling system Flettner rotors. The choice of a catamaran was made to reduce as much as possible the ship resistance and hence to maximize the produced energy. The choice of using Flettner rotors instead of wig sails or kites was made based on their very good aerodynamic performances and on the automation potential of the control.

This paper is organized as follows. First, the mathematical model developed for such a concept is introduced in details. Then the performances of two configurations of the concept are presented. The first configuration considers a relatively long ship propelled by a single Flettner rotor. The second configuration consists in a relatively long ship and propelled with four Flettner rotors. Results show that the first configuration is able to produce few hundreds of kilo-watts while the second configuration has the potential to produce few mega-watts.

\section{NOMENCLATURE}

a Induction factor of the rotor.

c Distance between the center of a hull w.r.t the mean free surface, $m$.

d Height of the center of gravity of the ship w.r.t the mean free surface, $m$.

e Distance between the foot of the rotor and the mean free surface, $m$.

$\mathrm{CL}_{\mathrm{L}} \quad$ Lift coefficient of the rotor.

$\mathrm{CD}$ Drag coefficient of the rotor.

Dv Diameter of the rotor, $m$.

$\mathrm{H} \quad$ Height of the rotor, $\mathrm{m}$.

LwL Length of the hulls, $m$.

Rf Radius of a hull, $\mathrm{m}$.

$\mathrm{S}$ Distance between the axis of the rotor and the hulls, m.

$\mathrm{SH} \quad$ Rotor surface area, $\mathrm{m}^{2}$.

$\mathrm{Sv} \quad$ Projected rotor surface area, $\mathrm{m}^{2}$

U Ship speed, $\mathrm{m} / \mathrm{s}$.

$\mathrm{V} \quad$ True wind speed, $\mathrm{m} / \mathrm{s}$.

Va Apparent wind speed, $\mathrm{m} / \mathrm{s}$.

$\mathrm{Va} \perp$ Apparent wind speed within the rotor reference frame, $\mathrm{m} / \mathrm{s}$.

$\alpha \mathrm{r} \quad$ Spin ratio: the ratio of the rotational speed of the Flettner rotor and the apparent wind speed.

$\alpha \quad$ Angle between the aerodynamic lift force on the rotor and the longitudinal axis of symmetry of the ship, ${ }^{\circ}$.

$\xi \quad$ Sinkage of the ship, m.

$\beta \quad$ Direction of the true wind w.r.t the ship direction, ${ }^{\circ}$.

$\varphi \quad$ Heel of the ship, ${ }^{\circ}$.

$\rho_{\mathrm{a}} \quad$ Air density, $\mathrm{Kg} / \mathrm{m}^{3}\left(\rho_{\mathrm{a}}=1.2 \mathrm{Kg} / \mathrm{m}^{3}\right)$.

$\nabla_{f} \quad$ Displacement of a single hull, $\mathrm{m}^{3}$

$\nabla_{\text {fupw }} \quad$ Displacement of the upwind hull, $\mathrm{m}^{3}$

$\nabla_{\text {fdow }} \quad$ Displacement of the downwind hull, $\mathrm{m}^{3}$
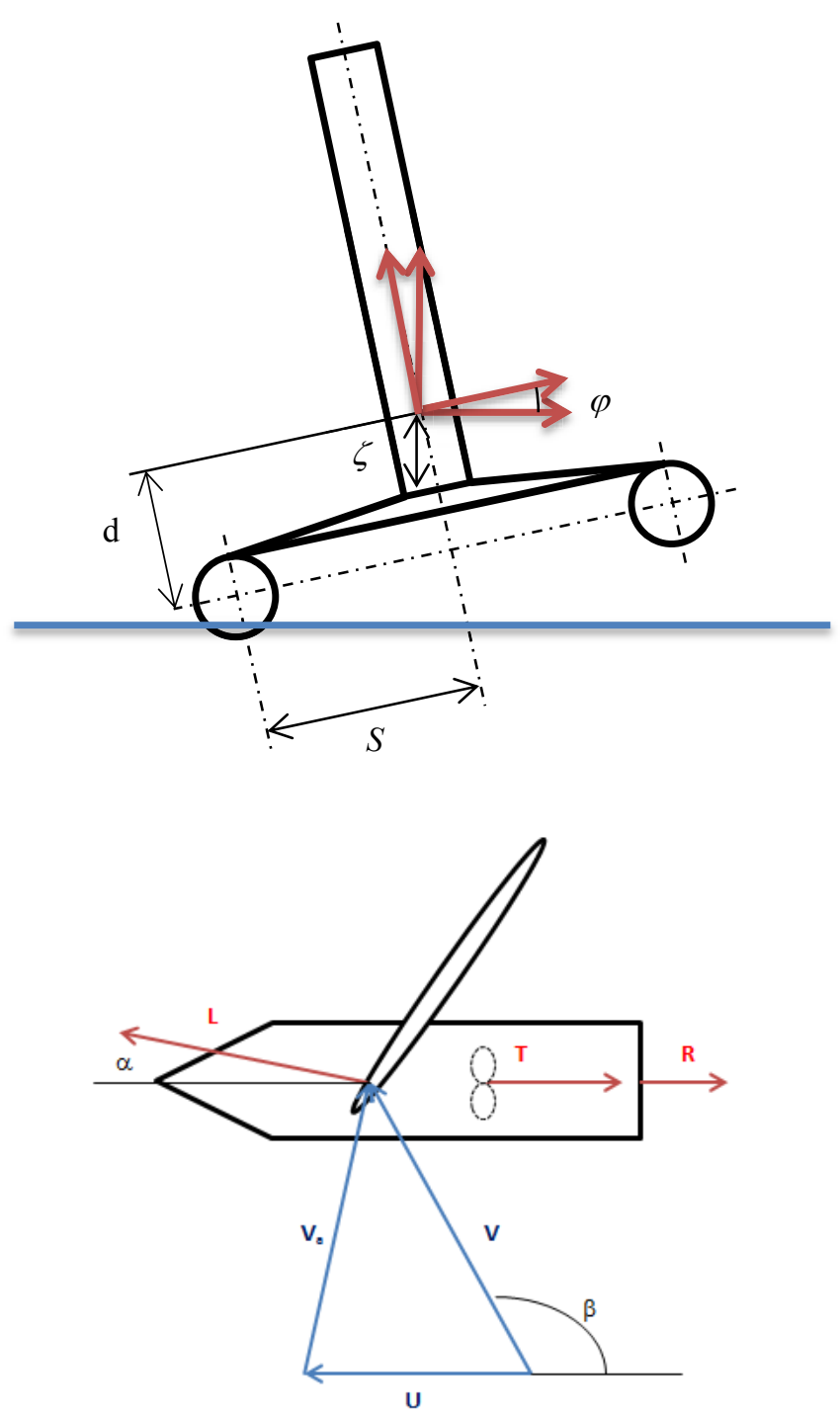

FIGURE 2: GEOMETRIC PARAMETERS FOR THE DEFINITION OF THE CATAMARAN WITH FLETTNER ROTOR (UPPER SCHEME) - SPEEDS AND FORCES UPON THE SYTEM (LOWER SCHEME).

\section{MATHEMATICAL MODEL}

In the following sections two catamarans with different sizes are considered. Both ships are propelled by Flettner rotors and equipped with a single hydro-generator. The design of the hull is kept simple and is assumed to be composed of two 
cylinders. The wind speed is assumed constant with an uniform profile.

The trim of the ship is neglected in the present approach, only three degrees of freedom are considered: the ship forward speed $\mathrm{U}$, the ship sinkage $\xi$ and the ship heel $\varphi$.

\section{Lift and drag aerodynamic forces on Flettner rotor}

A Flettner rotor consists of an upright-mounted cylinder which is spun along its longitudinal axis by a motor. It exploits the properties of Magnus effect and the lift force generated by fluid flow over a rotating body, at right angles to both the direction of flow and the axis of rotation. The lift and drag forces produced by the Flettner rotor respectively depends of the lift and drag coefficients of the rotor and are given by the following equations:

$$
\begin{aligned}
& \mathbf{L}=\frac{1}{2} \rho_{a} S_{v} C_{L}\left(\alpha_{r}\right) V_{a \perp}{ }^{2} \\
& \mathbf{D}=\frac{1}{2} \rho_{a} S_{v} C_{D}\left(\alpha_{r}\right) V_{a \perp}{ }^{2}
\end{aligned}
$$

with $V_{a \perp}$ the apparent wind speed defined as

$$
V_{a \perp}{ }^{2}=(U+V \cos \beta)^{2}+V^{2} \sin ^{2} \beta \cos ^{2} \varphi
$$

within the rotor reference plane. The lift and drag force are finally given by the following relationships:

$$
\begin{gathered}
\mathbf{L}=\frac{1}{2} \rho_{a} S_{v} C_{L}\left(\alpha_{r}\right)\left(U^{2}+2 U V \cos \beta\right. \\
\left.+V^{2}\left(\cos ^{2} \beta+\sin ^{2} \beta \cos ^{2} \varphi\right)\right) \\
\mathbf{D}=\frac{1}{2} \rho_{a} S_{v} C_{D}\left(\alpha_{r}\right)\left(U^{2}+2 U V \cos \beta\right. \\
\left.+V^{2}\left(\cos ^{2} \beta+\sin ^{2} \beta \cos ^{2} \varphi\right)\right)
\end{gathered}
$$

Lift and drag forces are then projected onto the Cartesian and expressed in terms of their Cartesian components. The corresponding heeling moment produced by the rotor at the center of gravity of the ship is calculated assuming that the center of pressure is at the center of the rotor as follow:

$$
\left.\mathbf{F}_{\text {aero }}=\begin{array}{c}
\mathbf{L} \cos \alpha-\mathbf{D} \sin \alpha \\
-(\mathbf{L} \sin \alpha+\mathbf{D} \cos \alpha) \cos \varphi \\
-(\mathbf{L} \sin \alpha+\mathbf{D} \cos \alpha) \sin \varphi \\
\left(\left(\frac{H}{2}+e-d\right)(\mathbf{L} \sin \alpha+\mathbf{D} \cos \alpha)\right.
\end{array}\right)
$$

\section{Buoyancy force}

Following Archimede's principle and the notations on Figure 3, the relative displacement of a single hull is calculated as follow

$$
\begin{aligned}
& \frac{\nabla_{f}}{L_{W L} \pi R_{f}{ }^{2}} \\
& =\underbrace{0} \begin{array}{c}
\text { if } z_{f}>R_{f} \\
{\left[\left(\frac{1}{2}-\frac{\delta}{\pi}\right)-\frac{1}{2 \pi} \sin 2 \delta\right] \text { if } R_{f}>z_{f}>-R_{f}} \\
1 \text { if } z_{f}<-R_{f}
\end{array}
\end{aligned}
$$

where $z_{f}$ corresponds to the sinkage of a hull which is given by

$$
z_{f}=\zeta-S \sin \varphi+d(1-\cos \varphi)+c \cos \varphi
$$

and where $\delta$ is defined as below following the notations of Figure 3.

$$
\frac{z_{f}}{R_{f}}=\sin \delta
$$

Since we consider a catamaran, when both hulls are taken into account the generalised buoyancy $\mathrm{F}_{\text {arch }}$ force becomes

$$
\begin{gathered}
\mathbf{F}_{\text {arch }} \\
\left.\left.\left.\left.=\quad \begin{array}{c}
0 \\
0 \\
\left(\rho g \left[-\left(\nabla_{f s v}-\nabla_{f a v}\right) S \cos \varphi+\left(\nabla_{f a v}\right)\right.\right.
\end{array}\right) \nabla_{f a v}\right)(d-c) \sin \varphi\right]\right)
\end{gathered}
$$

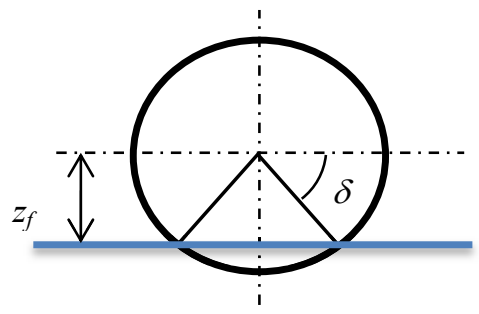

FIGURE 3: NOTATIONS USED FOR THE CALCULATION OF BUOYANCY FORCES OVER A SINGLE HULL.

\section{Ship resistance}

Following ITCC recommendations, ship resistance is composed of two main components: friction resistance and wave resistance. The friction resistance can be calculated by the following equation:

$$
\mathbf{R}_{\mathbf{F}}=\frac{1}{2} \rho C_{f} S_{f} U^{2}
$$

with $C f$ the coefficient of friction and $S_{f}=\mathrm{S}_{f s v}+\mathrm{S}_{f a v}$ the total wetted surface area. The coefficient of friction mainly depends on the Reynolds number and is dictated by the following relationship

$$
C_{f}=\frac{0,075}{(\log \operatorname{Re}-2)^{2}}
$$

The wave resistance is mainly based on Froude number similarity. In [6] it is shown that wave resistance grows strongly with the Froude number, and much more slowly between $\mathrm{Fr}=$ 0.5 (20knts) and $\mathrm{Fr}=1$ (40knts). In Froude number similarity, the wave resistance evolves with the cube of the length. As a first approximation, it will be considered that the total resistance can be written as

$$
\mathbf{R}_{\mathbf{T}}=\frac{1}{2} \rho C_{f} S_{f} U^{2}+\left\{\begin{array}{c}
8 \mathrm{Fr}^{2} L_{W L}{ }^{3} \text { si } \mathrm{Fr}<0.5 \\
(1.5+\mathrm{Fr}) L_{W L}{ }^{3} \text { si } \mathrm{Fr}>0.5
\end{array}\right.
$$

The corresponding generalised force is then given by the following 
$\mathbf{R}$

$$
=\left\{\begin{array}{c}
8 \mathrm{Fr}^{2} L_{W L}{ }^{3} \text { si } \mathrm{Fr}<0.5 \\
(1.5+2 \mathrm{Fr}) L_{W L}{ }^{3} \text { si Fr }>0.5 \\
0 \\
0 \\
0
\end{array}\right)
$$

\section{Hydro-generator drag forces}

Following Betz' limit theory, the hydro-generator induced drag force is dictated by the following relationship

$$
\mathbf{T}=\frac{1}{2} \rho S_{H} U^{2} 4 a(1-a)
$$

The corresponding generalized force Fgen is then

$$
\mathbf{F}_{\text {gen }}=\left(\begin{array}{c}
-\frac{1}{2} \rho S_{H} U^{2} 4 a(1-a) \\
0 \\
0 \\
0
\end{array}\right)
$$

\section{Balance forces relationship}

In order the find the steady-state conditions the aerodynamic force produced by the rotor must be balanced by the forces produced by the ship and the hydro-generator. Following Newton's first law of motion, the balance of forces of the system is then

$$
\mathrm{F}_{\text {aero }}+\mathrm{F}_{\text {arch }}+\mathrm{F}_{a v}+\mathrm{F}_{\text {gen }}+\mathrm{F}_{\text {grav }}=0
$$

Numerically, the static equilibrium is obtained by solving the following system of equations

$$
\left\{\begin{array}{c}
\mathbf{L}(U, j)+\mathbf{D}(U, j)+\mathbf{R}(U)+ \\
\mathbf{T}(U, a)+\mathbf{P}(U, j)+\mathbf{A}(U, \zeta, j)
\end{array}=\mathbf{0}\right.
$$

with $\mathbf{L}$ and $\mathbf{D}$ the lift and drag forces of the rotor, $\mathbf{R}$ the ship resistance, $\mathbf{T}$ the hydro-generator thrust force, $\mathbf{P}$ the gravity force and $\mathbf{A}$ the buoyancy force as shown on Figure 2.

\section{Power performance model}

The power produced by the lift and drag forces on the rotor minus the power consumed by the motor for spinning the rotor defines the amount of available power for propelling the ship. The power consumed by the rotor depends on one key parameter called the moment coefficient $C_{M}$. Following Traut [8], the power $\operatorname{Pr}$ consumed by the motor is calculated by the following relationship:

$$
P_{r}=\rho S_{v} V_{a}^{3} C_{M} \alpha_{r}
$$

The power absorbed by the hydro-generator corresponds to the power absorbed by the rotor minus the power consumed by the motor minus the power loss from the ship resistance. Following Betz's limit theory, the mechnical power absorbed by the hydro-generator $\mathrm{Pm}$ is as follow [8]

$$
P_{m}=\frac{1}{2} \rho S_{H} U^{3} 4 a(1-a)^{2}
$$

with a the induction factor a that corresponds to the velocity reduction factor at the hydro-generator plane.
The net power available for the hydrogen production through electrolysis is then the difference between the power delivered by the hydro-generator $P_{m}$ and the power that is consumed for spinning the rotor $P_{r}$ :

$$
P_{\text {net }}=P_{m}-P_{r}
$$

\section{APPLICATION}

In this section a sample of the design space of the concept is presented. Two drastically different designs are hence presented in details in order to explore the limits of potential of the concept at its preliminary development stage. The first concept consists of a relatively long catamaran propelled by a single Flettner rotor while the second concept consists of a very long catamaran propelled by four Flettner rotors.

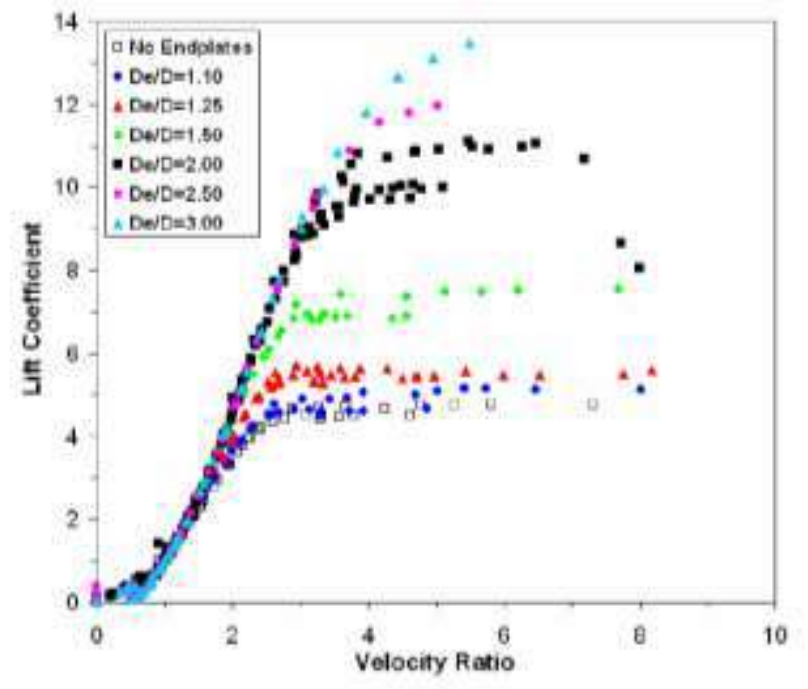

FIGURE 4: LIFT COEFFICIENTS AS FUNCTION OF END PLATE DIAMETER AND SPIN RATIO. EXPERIMENTAL DATABASE TAKEN FROM [5] FOR AN ASPECT RATIO ROTOR HEIGHT/ROTOR DIAMETER $=5$ AND $\mathrm{Re}=[1 \cdot 6 \cdot 104-9 \cdot 5 \cdot 104]$.

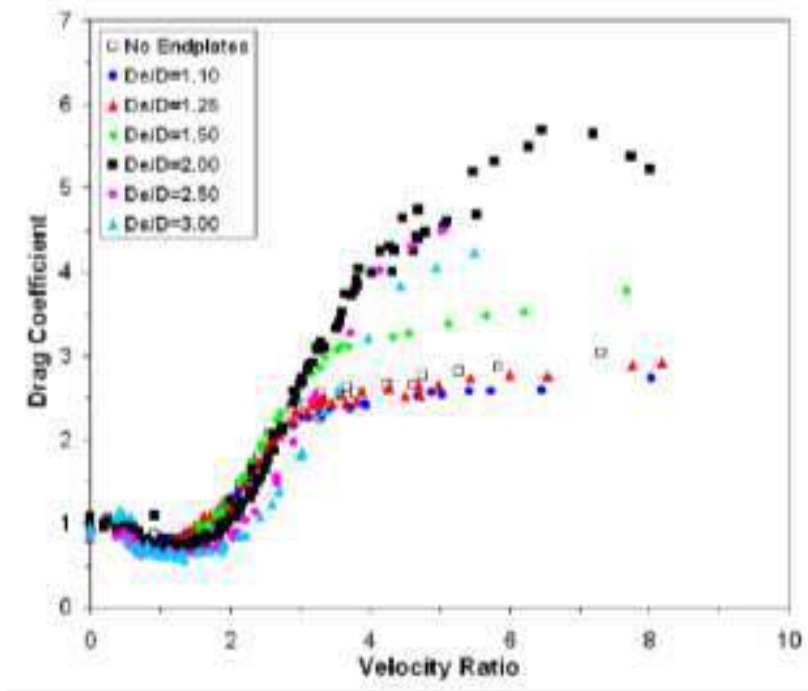

FIGURE 5: DRAG COEFFICIENTS AS FUNCTION OF END PLATE DIAMETER AND SPIN RATIO. EXPERIMENTAL DATABASE TAKEN FROM [5] FOR AN ASPECT RATIO ROTOR HEIGHT/ROTOR DIAMETER $=5$ AND $\mathrm{Re}=\left[1 \cdot 6 \cdot 10^{4}-9 \cdot 5 \cdot 10^{4}\right]$. 


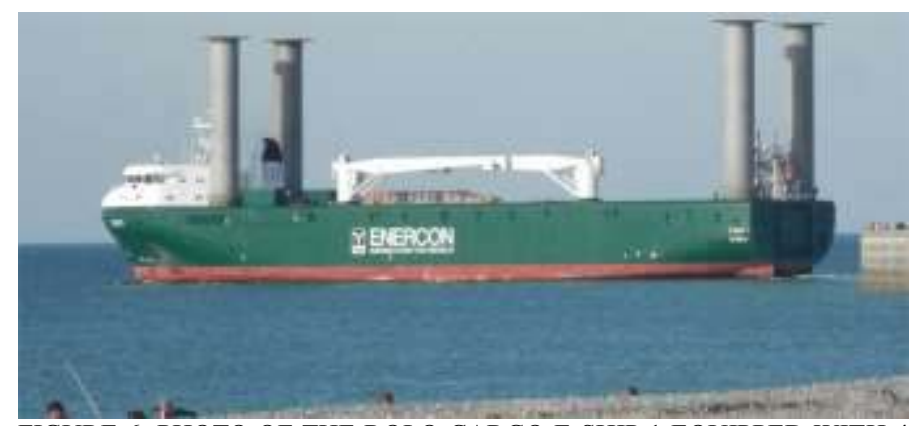

FIGURE 6: PHOTO OF THE ROLO CARGO E-SHIP 1 EQUIPPED WITH 4 FLETTNER ROTORS [9].

For both case studies, Flettner rotors dimensions are: height $=$ $27 \mathrm{~m}$ and diameter $=4 \mathrm{~m}$ which gives a total rotor area of 108 $\mathrm{m}^{2}$ for one single rotor. Those dimensions correspond to the rotors installed on the RoLo cargo vessel E-Ship 1 (cf. Figure 6). The rotors are assumed to be in aluminum (density $=2700$ $\mathrm{Kg} / \mathrm{m}^{3}$ ) with a thickness of $8 \mathrm{~mm}$ giving a total mass of 14.6 tons for one single rotor.

From a numerical point of view, the values of the aerodynamic coefficients $C_{L}$ and $C_{D}$ used for modelling rotors are set to 9 and 2.5 respectively. This choice was made according to the data plotted on Figure 4 and Figure 5. Here the rotor is assumed to be a plain cylinder with end plates with a ratio between the rotor diameter and the end plate diameter equal to 3. Following [7] the coefficient of moment is $\mathrm{C}_{\mathrm{M}}=0.06$ and the spin ratio defined as the ratio of the rotor surface speed and the apparent wind speed is $\alpha=3$.

For both case studies, each catamaran is equipped with one single hydro-generator $2 \mathrm{~m}$ diameter large. At each simulation the induction factor is optimized so that the peak power is reached.

\section{First case study: $200 \mathrm{~kW}$ vessel}

For this case study, a relatively long catamaran equipped with one single Flettner rotor is considered (cf. Figure 7. The length is set to $22 \mathrm{~m}$ which corresponds to the length of America's Cup 72 class (AC72). The key characteristics of the ship are summarized in Table 1.

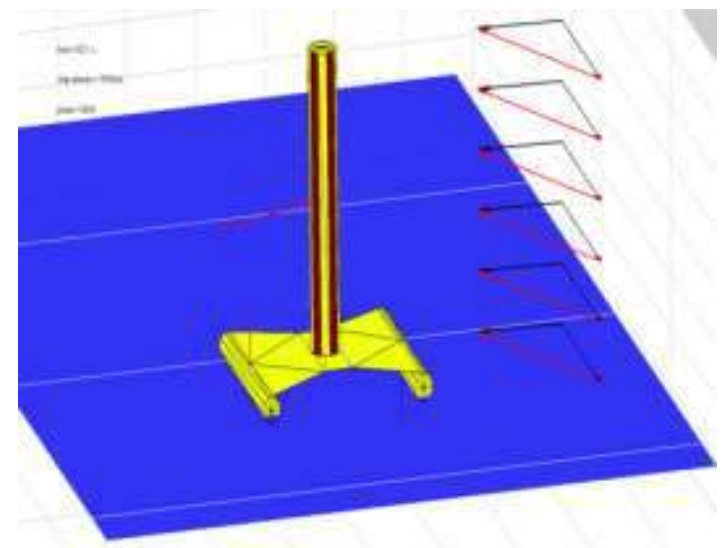

FIGURE 7 : SCREENSHOT OF SIMULATION OF THE 22 M LONG SHIP AT STATIC EQUILIBRIUM.

\begin{tabular}{|c|c|c|}
\hline Length (m) & 22 & As for $\mathrm{AC} 72$ \\
\hline Rotor area $\left(\mathrm{m}^{2}\right)$ & 108 & $\begin{array}{l}\text { Height } 27 \mathrm{~m} \times \text { Diameter } 4 \mathrm{~m} \text {; same as } \\
\text { Enercon e-ship } 1\end{array}$ \\
\hline Rotor mass (t) & 14.6 & Aluminium, $8 \mathrm{~mm}$ thickness \\
\hline $\begin{array}{l}\text { Rotor drive } \\
\text { power }(\mathrm{kW})\end{array}$ & 38 & $\mathrm{C}_{\mathrm{M}}=0.06+$ bearing friction \\
\hline $\begin{array}{l}\text { Lift / Drag } \\
\text { coefficient }\end{array}$ & $9 / 2.5$ & $\begin{array}{l}\text { For spin ratio of } 3 \text { in experimental data } \\
\text { from [5] }\end{array}$ \\
\hline Displacement $(\mathrm{t})$ & 22 & $200 \%$ of rotor mass, $4 x$ AC72 \\
\hline $\begin{array}{l}\text { Wetted surface } \\
\left(\mathrm{m}^{2}\right)\end{array}$ & 89 & $\begin{array}{l}\text { Estimate, assuming hulls are half } \\
\text { cylinders }\end{array}$ \\
\hline $\begin{array}{l}\text { Skin friction } \\
\text { coefficient }\end{array}$ & 0.002 & ITTC 1957 for $\operatorname{Re} \sim 10^{8}$ \\
\hline $\begin{array}{l}\text { Resistance } \\
\text { coefficient }\end{array}$ & 0.006 & $\begin{array}{l}\text { For Fn in range }[0,6-1] \text {, skin friction is } \\
25 \text { to } 50 \% \text { of total resistance }[6]\end{array}$ \\
\hline $\begin{array}{l}\text { Hydrogenerator } \\
\text { area }\left(\mathrm{m}^{2}\right)\end{array}$ & 3.14 & $2 \mathrm{~m}$ diameter \\
\hline $\begin{array}{l}\text { Hydrogenerator } \\
\text { efficiency }(\%)\end{array}$ & 70 & $\begin{array}{l}\text { Typical peak efficiency of ship } \\
\text { propeller }\end{array}$ \\
\hline
\end{tabular}

TABLE 1: KEY CHARACTERISTICS OF THE 200 KW SHIP.

Figure 8 shows the power absorbed by the hydro-generator as function of the true wind speed TWS and true wind angle TWA. It clearly shows that the optimum true wind angle TWA for absorbing a maximum of energy is $90^{\circ}$ for any wind speed. Figure 10, Figure 11 and Figure 12 also illustrate this result. This result means that the optimum point of sail for this kind of ship is then beam reach which might be interesting from a design point of view since U-turns might be avoided if symmetric hulls are used.

Figure 10 shows the electrical power generated by the hydrogenerator and the net electrical power as function of the true wind speed TWS. One can notice that for low true wind speeds the ship performances are poor since the net power is negative meaning that the electrical power consumed by the rotor is higher that the power produced by the hydro-generator. At higher true wind speed, the power performances are much better. The hydro-generator is able to produce almost $1 \mathrm{MW}$ while the power consumed by the rotor is about $350 \mathrm{~kW}$ giving a net power of about $625 \mathrm{~kW}$. If we focus on the true wind speed TWS $=8 \mathrm{~m} / \mathrm{s}(\sim 16 \mathrm{knots})$, which is a minimum value reached in many regions around the world (cf. Figure 9), the peak mechanical power performance is about $147 \mathrm{~kW}$ for a true wind angle TWA $=86^{\circ}$. In this case the power consumed for spinning the rotor is reasonable and is about $40 \mathrm{~kW}$ giving a net power of about $100 \mathrm{~kW}$. It means that, if we assume that such a relatively long catamaran can operate most of the time in areas where the wind speed is higher or equal to $8 \mathrm{~m} / \mathrm{s}$ and assuming an efficiency of $60 \%$ of the electrolyzer, one ship would be able to gather tons of hydrogen annually. This would be achievable 
if the ship is able to continually travel towards areas were the wind is at least $8 \mathrm{~m} / \mathrm{s}$ namely between N30 and N60 latitudes and between E130 and W120 longitudes in the northern hemisphere or between S40 and S70 latitudes and E0 and E360 longitudes in the southern hemisphere as pointed by Kim in [4]. This could be possible with proper strategic weather routing as already done in the ocean shipping industry.

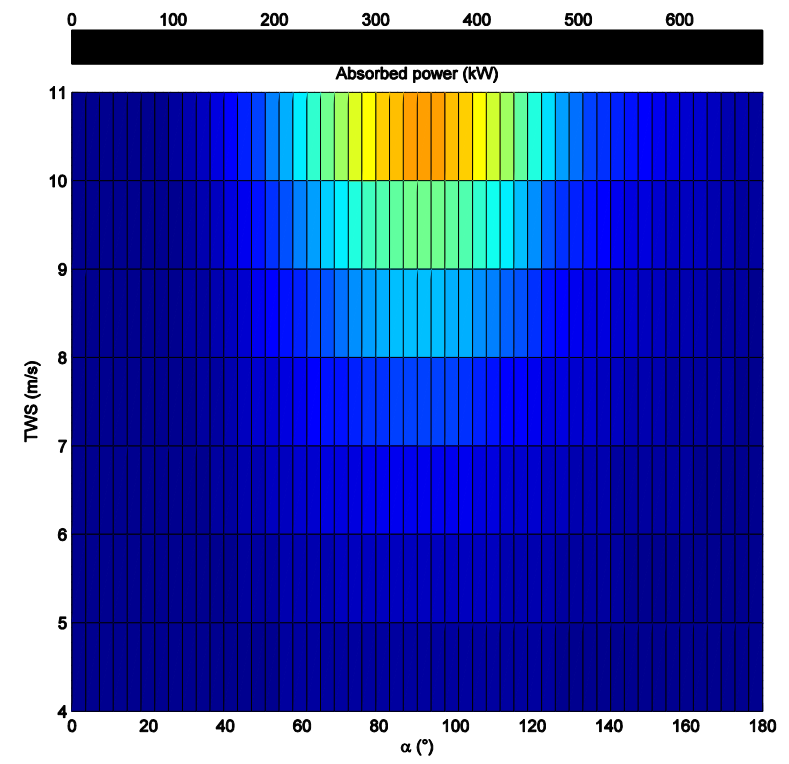

FIGURE 8: ABSORBED POWER IN KW AS FUNCTION OF TRUE WIND SPEED TWS AND THE TRUE WIND ANGLE TWA FOR THE $22 \mathrm{M}$ LONG SHIP WITH ONE SINGLE FLETTNER ROTOR.

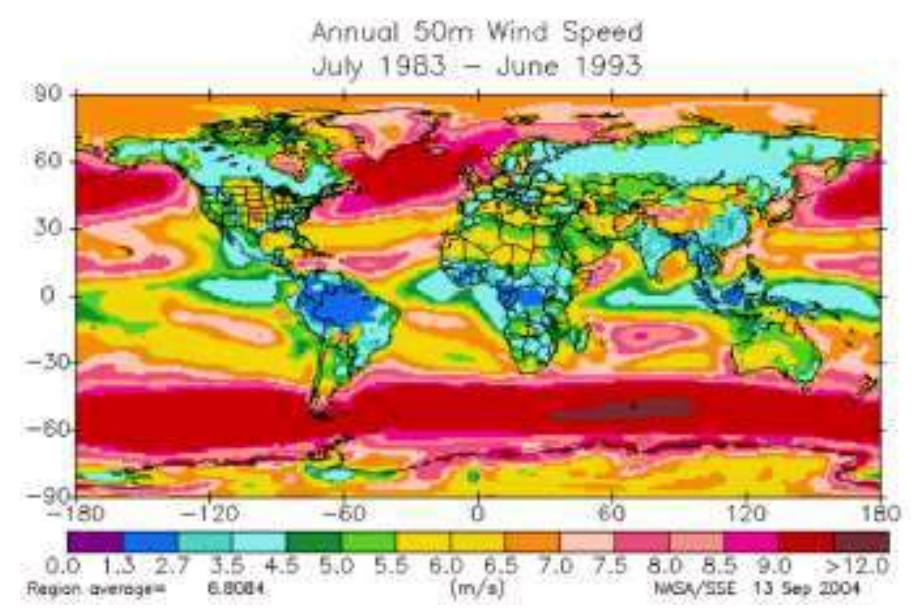

FIGURE 9: GLOBAL DISTRIBUTION OF ANNUAL $50 \mathrm{M}$ AVERAGE WIND SPEED [10].

The upper plot of Figure 11 shows the wind propulsion force, the ship resistance and the hydro-generator induced drag forces as function of the true wind angle for a true wind speed TWS $=8$ $\mathrm{m} / \mathrm{s}$. One can notice is that half of the absorbed power by the rotor is lost in ship resistance. This result highlights the need to have a design with very good hydrodynamic performances which was the reason why a catamaran was chosen for this study. One possible alternative would be the use of hydrofoils to even more decrease the ship resistance. This solution would bring additional design challenges from a structural point of view as well as from a control point of view for controlling the balance of the ship and to keep the hulls out of the water.

The lower plot of Figure 11 shows the water speed at the hydrogenerator plane for a true wind speed TWS $=8 \mathrm{~m} / \mathrm{s}$. It shows that the flow's speed can exceed the wind speed when the true wind angle is in the range $\left[70^{\circ}, 120^{\circ}\right]$.

The upper plot of Figure 12 shows the induction factor as function of TWS. One can see that the induction factor is much lower than the usual value of Betz' limit theory. This result is also illustrated on Figure 11 where the water flow speed is higher than $16 / 29$ of the ship speed $\mathrm{V}=13 \mathrm{~m} / \mathrm{s}$. It is then interesting to notice that, in comparison to "fixed" concept, such as wind turbine, concepts using wind as propulsion energy is able to exceed Betz' limit.

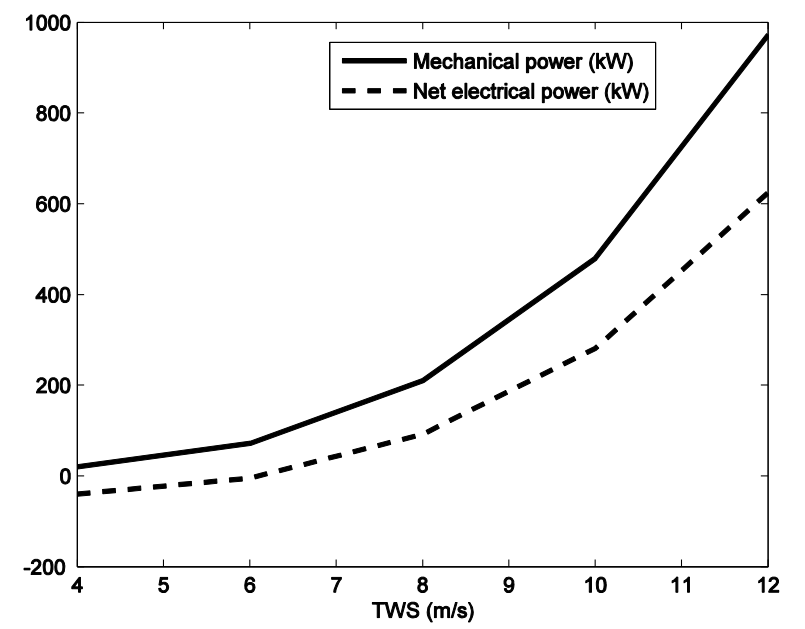

FIGURE 10: MECHANICAL POWER PM PRODUCED BY THE HYDROGENERATOR AND THE NET ELECTRICAL POWER PNET AS FUNCTION OF THE TRUE WIND SPEED.
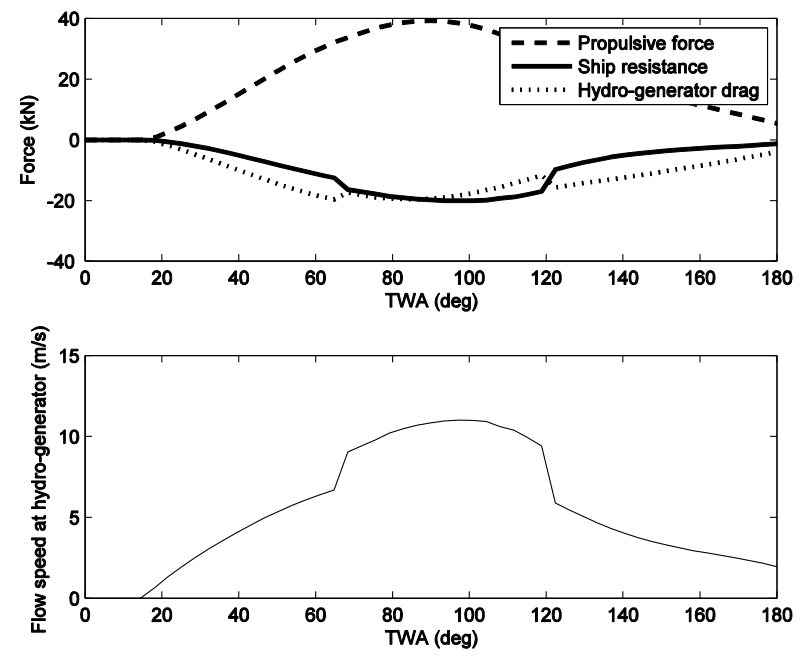

FIGURE 11: UPPER PLOT - AERODYNAMIC PROPULSIVE FORCE, SHIP RESISTANCE AND HYDRO-GENERATOR DRAG FORCE, LOWER PLOT - FLOW VELOCITY SPEED AS FUNCTION OF TRUE WIND ANGLE TWA AT WIND SPEED V $=8 \mathrm{M} / \mathrm{S}$. 

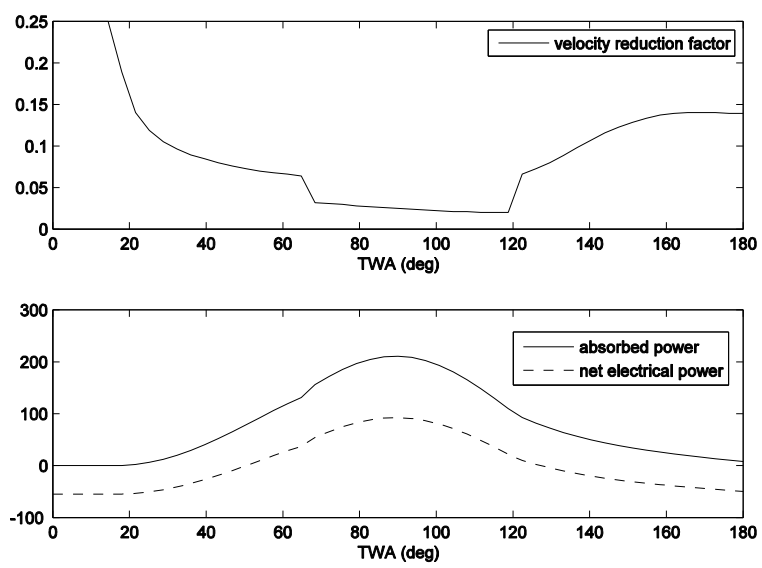

FIGURE 12: VELOCITY REDUCTION FACTOR AT THE HYDROGENERATOR (UPPER PLOT), ABSORBED AND NET ELECTRICAL POWER (LOWER PLOT) AT WIND SPEED V=8 M/S.

\section{Second case study: $1 \mathrm{MW}$ vessel}

In this case study, a $80 \mathrm{~m}$ long catamaran equipped with 4 Flettner rotors is considered (cf. Figure 13). The key characteristics of the ship are summarized in Table 2.

FIGURE 14 shows the electrical power generated by the hydrogenerator and the electrical net power as function of the true wind speed TWS. As for the $200 \mathrm{~kW}$ ship, one can notice that for low wind speeds the ship performances are very poor since most of the produced energy is used for spinning the rotor or even worst when the net power is negative. From a practical point of view, it means that for such a low wind speed the rotor should be switch off. For higher wind speed the concept can absorb $4 \mathrm{MW}$ which corresponds to a net power of $2.5 \mathrm{MW}$.

If, as in the previous case study, we focus on the true wind speed value TWS $=8 \mathrm{~m} / \mathrm{s}(\sim 16 \mathrm{knots})$, one can notice that the ship has a peak mechanical power performance of $925 \mathrm{~kW}$ at the true wind angle TWA $=90^{\circ}$ but a net electrical power $P_{\text {net }}=$ $441 \mathrm{~kW}$. The ship speed is equal to $13 \mathrm{~m} / \mathrm{s}$ ( $\sim 26$ knots) which corresponds to $150 \%$ of the true wind speed. On the upper plot of Figure 15 is shown the propulsive force, the ship resistance force and the hydro-generator induced drag force as function of TWS. Again it is noticeable that half of the propulsion force is lost by the ship resistance force. We can also see that the optimum point of sail is beam reach corresponding to a TWA = $90^{\circ}$. On the lower plot of Figure 15 is shown the water flow speed at the rotor plane. One can see that the water flow is higher than the TWS and corresponds to $77 \%$ of the ship speed $\mathrm{V}=13 \mathrm{~m} / \mathrm{s}$ ( $\sim 26$ knots $)$ which is higher than Betz' limit.

The upper plot of Figure 16 shows the velocity induction factor at the hydro-generator plane as function of TWA. Again we can notice that the induction factor reaches values much lower than Betz' limit. The lower plot of Figure 16 shows the absorbed power and the net electrical power as function of TWA. As on Figure 15, we clearly see that optimum TWA is close to $90^{\circ}$.

If we assume that such a very long catamaran can operate most of the time in areas where the wind speed is higher or equal to 8 $\mathrm{m} / \mathrm{s}$ and assuming an electrolyzer efficiency of $60 \%$ this ship would be able to harness more than 100 tons of hydrogen annually.

FIGURE 13: SCREENSHOT OF SIMULATION OF THE 80 M LONG SHIP AT STATIC EQUILIBRIUM.

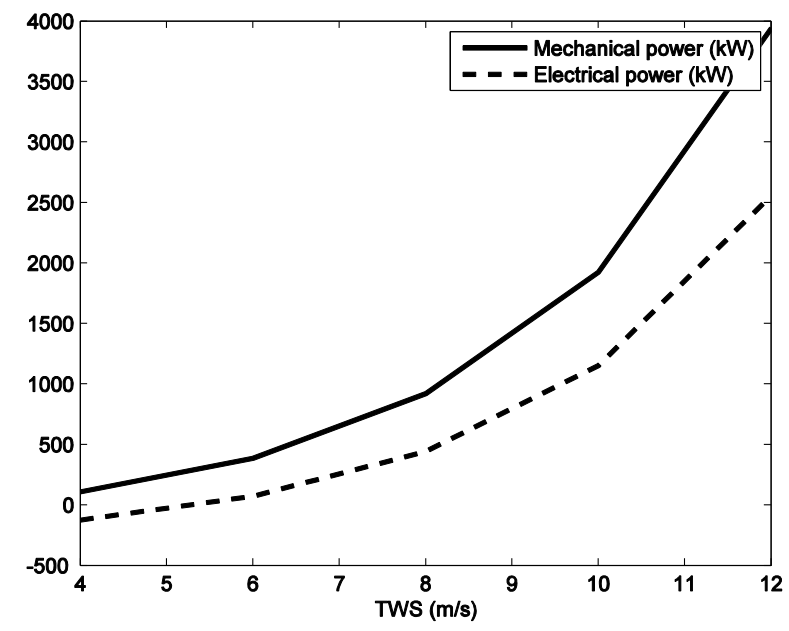

FIGURE 14: MECHANICAL POWER $P_{M}$ PRODUCED BY THE HYDROGENERATOR AS FUNCTION OF THE TRUE WIND SPEED.
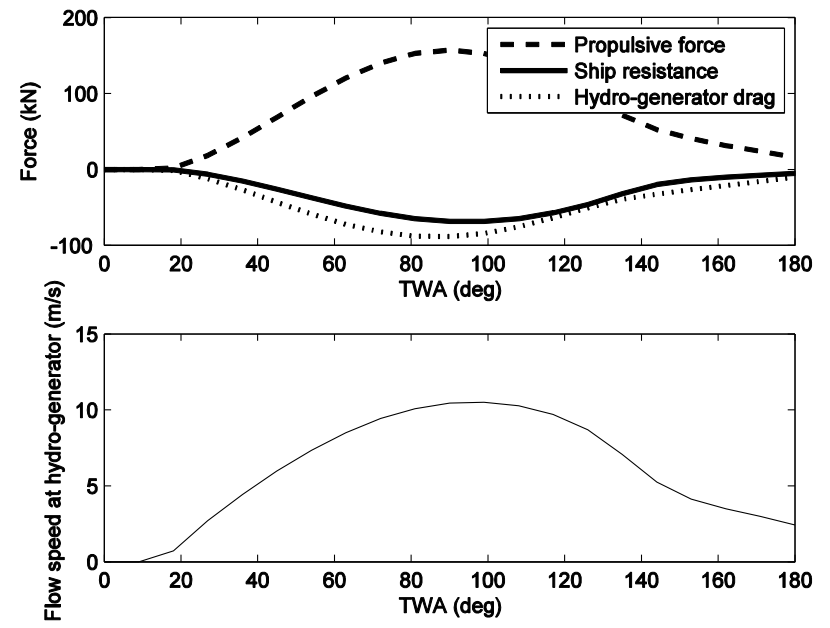

FIGURE 15: PROPULSION FORCE, SHIP RESISTANCE AND HYDROGENERATOR DRAG FORCE AS FUNCTION OF TRUE WIND ANGLE (UPPER PLOT), FLOW SPEED AT THE HYDRO-GENRATOR AS FUNCTION OF TRUE WIND ANGLE AT WIND SPEED V=8 M/S. 

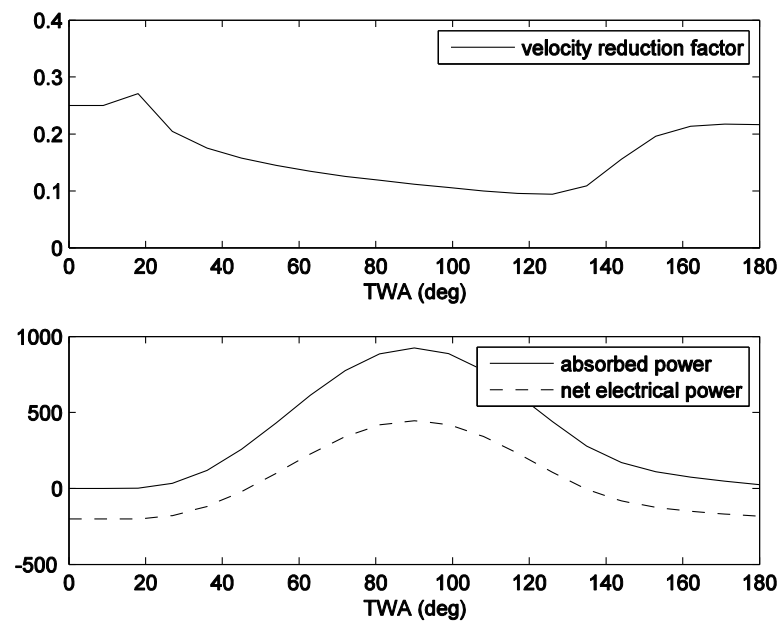

FIGURE 16: VELOCITY REDUCTION FACTOR AT THE HYDROGENERATOR (UPPER PLOT), ABSORBED AND NET ELECTRICAL POWER (LOWER PLOT) AT WIND SPEED V=8 M/S.

\begin{tabular}{|c|c|c|}
\hline Length (m) & 80 & \\
\hline Width (m) & 12 & \\
\hline Rotor area $\left(\mathrm{m}^{2}\right)$ & 432 & $\begin{array}{l}4 \text { rotors of height } 27 \mathrm{~m} \times \text { Diameter } 4 \mathrm{~m} \text {; } \\
\text { same as Enercon e-ship } 1\end{array}$ \\
\hline Rotor mass (t) & 9 & Aluminium, $8 \mathrm{~mm}$ thickness \\
\hline $\begin{array}{l}\text { Rotor drive } \\
\text { power }(\mathrm{kW}) \text {, per } \\
\text { rotor }\end{array}$ & 38 & $\mathrm{C}_{\mathrm{M}}=0.06+$ bearing friction \\
\hline $\begin{array}{l}\text { Lift / Drag } \\
\text { coefficient }\end{array}$ & $9 / 2.5$ & $\begin{array}{c}\text { For spin ratio of } 3 \text { in experimental data } \\
\text { from [5] }\end{array}$ \\
\hline Displacement (t) & 123 & $\begin{array}{l}36 \text { tons for rotors, } 37 \text { tons for } \mathrm{H}_{2} \\
\text { production system, } 14 \text { tons for } \mathrm{H}_{2} \\
\text { storage, } 36 \text { tons for hull }\end{array}$ \\
\hline $\begin{array}{l}\text { Hydrogenerator } \\
\text { area }\left(\mathrm{m}^{2}\right)\end{array}$ & 3.14 & $2 \mathrm{~m}$ diameter \\
\hline $\begin{array}{l}\text { Hydrogenerator } \\
\text { efficiency }(\%)\end{array}$ & 70 & $\begin{array}{c}\text { Typical peak efficiency of ship } \\
\text { propeller }\end{array}$ \\
\hline
\end{tabular}

TABLE 2: KEY CHARACTERISTICS OF THE 1MW VESSEL.

\section{CONCLUSIONS}

In this study, an innovative concept of a wind-driven hydrogen producing vessel was presented. A numerical model of a wind-driven vessel was presented in details. This model was used to explore the space of design of the concept. The configuration considered consists of a catamaran propelled by a single or several Flettner rotors and equipped with a single hydro-generator to convert the kinetic energy of the ship speed into electricity.

Two case studies were presented in details: a $22 \mathrm{~m}$ long catamaran equipped with one single Flettner rotor and one single hydro-generator and a $80 \mathrm{~m}$ long catamaran equipped with 4 Flettner rotors and one single hydro-generator. Results show that such a concept might be a relevant alternative to classical offshore wind converters. The $22 \mathrm{~m}$ long ship can produce about $100 \mathrm{~kW}$ of net power at a true wind speed equal to $8 \mathrm{~m} / \mathrm{s}$. The $80 \mathrm{~m}$ long catamaran can produce almost $500 \mathrm{~kW}$ of net power at a true wind speed equal to $8 \mathrm{~m} / \mathrm{s}$. It has also been highlighted that both configurations can exceed Betz' limit; Results also showed that the optimum point of sail is beam reach corresponding to a TWA $=90^{\circ}$.

This preliminary analysis shows promising potential. Nevertheless further research is needed. First the exploration of the design space needs must continue with more different configurations and hull design. It has been shown that the losses due to the ship resistance force corresponds to half of the absorbed force so further work is needed to mitigate those losses. It has also been showed that such a concept needs a high capacity factor to be competitive. So further research need to be carry out on weather ship routing in order to increase as much as possible the production duration and to get a capacity factor close to 1 . Further work need also to be performed on the wind propulsion system. Here Flettner rotor was used but different propulsion system must be tested such as wind sails or turbo sails. Few data on the aerodynamic performances of Flettner rotors are available. Some further research must be performed to get a better understanding on the power consumed by the motor which is a key parameter to properly assess the performances of the concept. Work needs also to be performed on the automation of the entire ship. It is believed that, to be cost effective, the concept must be autonomous in order to reduce the OPEX. Finally a proper cost function of the concept needs to be developed to get a clear idea of how much is the cost of a prototype and what is the long term cost?

\section{REFERENCES}

[1] REN21, Renewables 2016 Global Status Report

[2] R.E. Salomon (1982) Process of converting wind energy to elemental hydrogen and apparatus therefor. Patent US4335093A Salomon

[3] P.F. Pelz, M. Holl, M. Platzer (2016) Analytical method towards an optimal energetic and economical wind-energy converter. Energies, Vol. 94, pp. 344-351

[4] J. Kim, C. Park (2010) Wind power generation with a parawing on ships, a proposal. Energy, Vol. 35, pp. 14251432

[5] C. Badalamenti, S.A. Prince (2008) The effects of endplates on a rotating cylinder in crossflow. In Proc. Of the 26th AIAA Applied Aerodynamics Conference, 18-21 August 2008, Honolulu, Hawaii.

[6] Zouridakis, F 2005. A preliminary design tool for resistance and powering prediction of catamaran vessels. MIT master thesis.

[7] Craft, T., Johnson, N. \& Launder, B( 2014). Back to the Future? A Re-examination of the Aerodynamics of Flettner- 
Thom Rotors for Maritime Propulsion. Flow Turbulence Combust (2014) 92: 413. doi:10.1007/s10494-013-9486-4

[8] M. Traut, et al. (2014). Propulsive power contribution of a kite and a Flettner rotor on selected shipping routes. Appl. Energy, 113, pp. 362-372 http://dx.doi.org/10.1016/j.apenergy.2013.07.026

[9] https://en.wikipedia.org/wiki/E-Ship_1

10] Stackhouse, P. W. Surface meteorology and Solar Energy (SSE) Release 6.0 Methodology. Version 3.2.0, June 2, 2016 